\title{
Porphyrin-modified DNA as Construction Material in Supramolecular Chemistry and Nano-architectonics
}

\author{
Eugen Stulz*
}

\begin{abstract}
An overview is given on the developments of using porphyrin-modified DNA for the construction of functional assemblies. Strategies for the synthesis and characterisation are presented alongside selected applications where the porphyrin modification has proven to be particularly useful, but also revealed its limitations. We also discuss implications on property and behaviour of the porphyrin-DNA, where similar issues could arise using other hydrophobic and bulky substituents on DNA.
\end{abstract}

Keywords: DNA · Molecular glue · Nano-architectonics · Porphyrin · Supramolecular assembly

\section{Introduction}

Supramolecular chemistry is defined as chemistry beyond the molecule where large chemical systems are made up of a discrete number of self-assembled molec-

Correspondence: Prof. E. Stulz

School of Chemistry \& Institute for Life Sciences

University of Southampton

Highfield, Southampton, SO17 1BJ, UK

E-mail: est@soton.ac.uk ular subunits. The forces involved in holding the molecular units together are usually the weaker non-covalent interactions such as hydrogen bonding or $\pi-\pi$ interactions. In this respect, DNA has shown to be an exciting construction material, owing to its distinct properties.[1] The basic principle of working with DNA is simple: the molecule forms a well-understood double helix through complementary base pairing of two antiparallel strands, where the recognition is based on the Watson-Crick (WC) base pairing of A-T and G-C.[2] Yet there is far more to DNA than just this concept. DNA can act both as rigid stick (duplex) with a persistence length of about
40-50 nm, and flexible glue ( single strand), giving access to a Lego-like building block system to create architectures with nanometre precision (Fig. 1). By taking DNA out of its biological context, new systems have emerged which are starting to play a major role in materials science, electronics, diagnostics, medicinal chemistry and more. Of particular interest is the emerging concept of DNA origami, ${ }^{[6]}$ where a long template strand (usually derived from a modified plasmid of several kilo base length as ssDNA) is stitched together with short staple strands (15-16 nt in length) to form designed structures in the two- and three-dimensional space.
"Stick"

a) Persistence length $35-50 \mathrm{~nm} / 105-150 \mathrm{bp}$

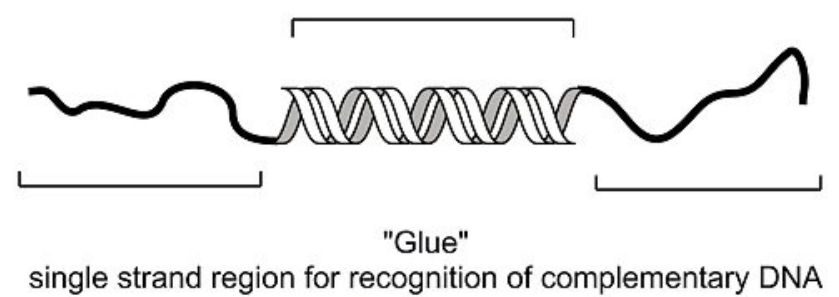

c)
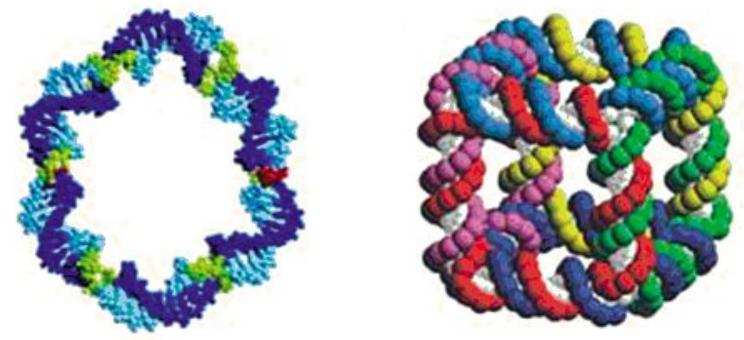

b)
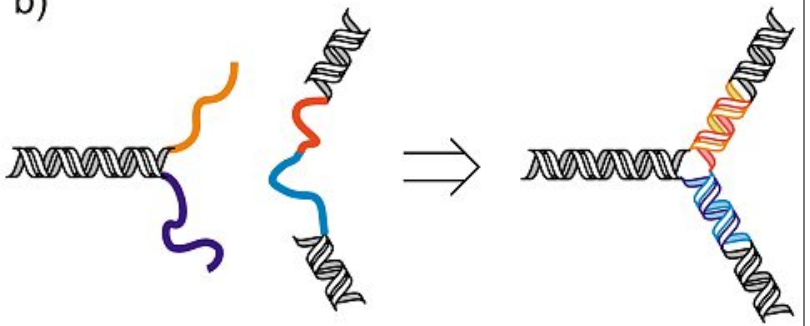
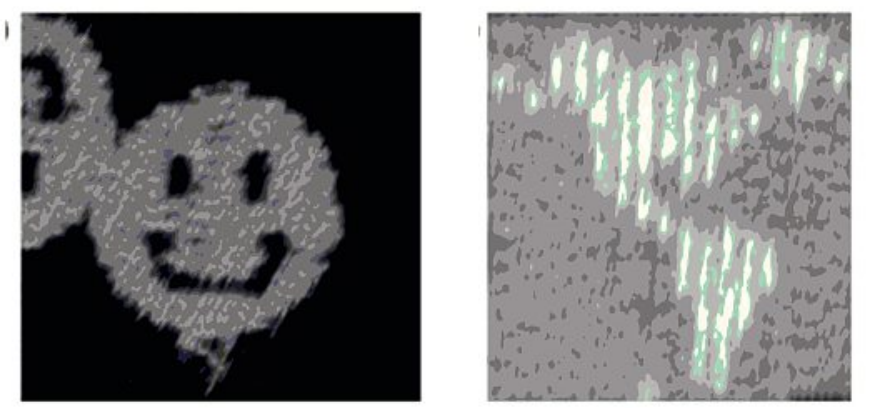

Fig. 1. a) DNA as stick-and-glue molecules, indicating rigid rod and flexible recognition parts; b) basic principle to build DNA architectures by selective recognition of complementary strands; c) examples of DNA nano-structures, including catenane, ${ }^{[3]}$ cube, ${ }^{[4]}$ and seminal DNA origami constructs. ${ }^{[5]}$ 
Our understanding of the DNA structure and sequence specific duplex formation, and the availability of automated synthesis, ${ }^{[7]}$ makes it a very attractive building block from which to create supramolecular structures with predictable and controllable 3D structure. The supramolecular aspects of DNA have thus greatly advanced in the past few decades, particularly with the inclusion of modified nucleotides. The introduction of modifications onto DNA can be achieved via several different methods at various positions (see Fig. 2 for a representative selection). Sites available for modification include: 3 '- and 5'-terminal positions; 2 '- and 4'-positions of the ribose ring; and finally, modifications to one of the four natural bases, A, C, G, and T. For the latter, usually $\mathrm{T}$ is the site of choice for modification due to the relatively cheap commercial availability of the 5-iodinated thymidine, or to be precise 5-iodo-deoxyuridine, and the ease of using Sonogashira coupling with this nucleoside to attach alkynes. ${ }^{[9]}$ In addition, the nucleobase itself can be substituted with designer molecules (artificial nucleobases), or the entire nucleotide can be replaced with moieties that have two hydroxyl groups which can be used to fulfil the DNA synthesis chemistry (base surrogates). In the latter case, however, helical structures are only formed when the base surrogate is embedded in a DNA template.

Whilst a huge diversity of substituents are nowadays available for site-directed inclusion into DNA, we are focussing on the use of porphyrins attached to the periphery of the DNA, thus creating functional supramolecular systems with potential in electronics/photonics, but which are also applicable in sensing and DNA bio-nanotechnology. The following sections will review the synthetic and structural aspects of porphyrin-DNA, and give highlights of recent applications in the above-mentioned areas. When we started our project a little more than ten years ago, not much was known about how much we can do to DNA in terms of large modifications and still retaining its structural integrity, before the system begins to falter. Intriguing work by Famulok and coworkers showed that a fully modified DNA strand will even be recognised as a template in enzymatic based DNA synthesis using polymerase chain reaction $(\mathrm{PCR}),{ }^{[10]}$ though this included rather small modifiers. This question still remains open to a certain extent, but it has become clear that DNA is far more tolerant than one would expect in terms of number and property of the modifications, clearly leading the way to fascinating novel materials.

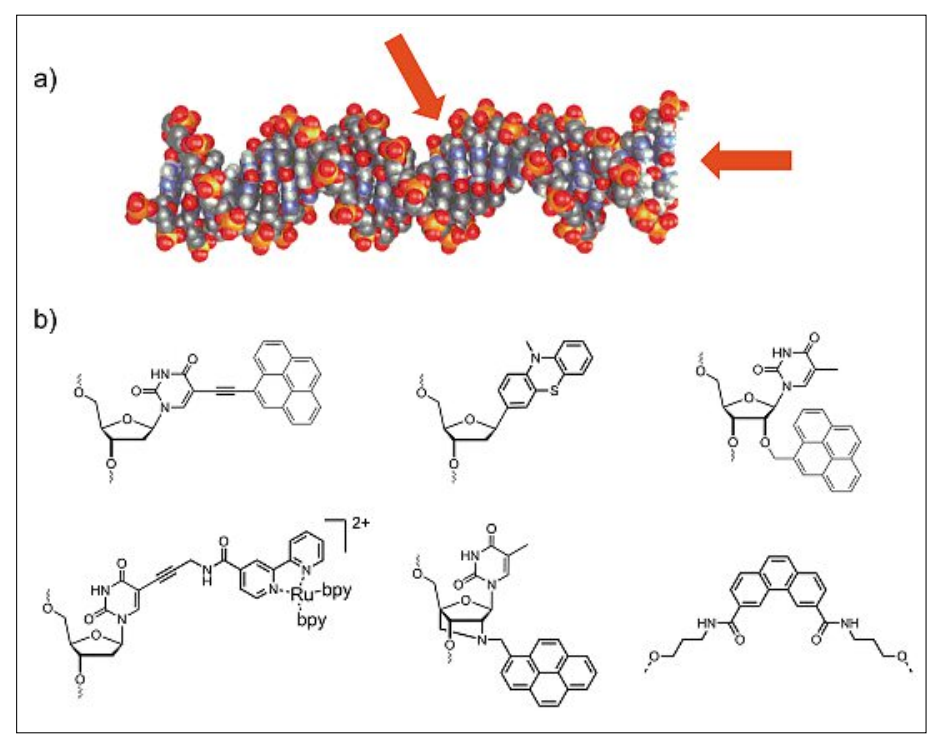

Fig. 2. a) Structure of the DNA with indication of site modification (red arrows), i.e. grooves, interior base stacking region, or end-of-helix modification; b) examples of modified nucleosides and base surrogates used to make functional DNA. [8]

\section{First-generation Porphyrin-DNA Systems}

The earliest examples of porphyrinappended DNA probably date back to the groups of Meunier[11] and Hélène ${ }^{[12]}$ who attached a cationic manganese porphyrin or chlorin, respectively, to DNA, and created with it artificial nucleases (Fig. 3a). Although this method was successful in synthesising the porphyrin oligonucleotide conjugates, it was limited in the fact that only one porphyrin modification could be added to the DNA at its end. However, a similar system developed by Berova et al. showed that the porphyrins at the end of the DNA can act as a chiroptical marker, which gives insight into structural aspects of the DNA and the environment of the porphyrin (Fig. 3b). ${ }^{[13]}$ Since the porphyrin itself is achiral and produces no CD signal, its attachment to DNA invokes transfer of the chiral information of the DNA to the porphyrin. As porphyrins strongly absorb light at around $420 \mathrm{~nm}$ (denoted Soret or Bband), the induced CD signal in this region is optimal to detect structural changes as it is well outside the window of the DNA absorbance. In this way, monitoring a change in structure from B-DNA to Z-DNA with increasing salt concentration was successful. Those examples already demonstrate the versatility of porphyrins attached to DNA with variable functionality (i.e. enzyme mimic or optical marker). A very different approach to porphyrin-DNA was explored by Kool et al., ${ }^{[14]}$ where the nucleobase was replaced by a porphyrin (Fig. 3c).

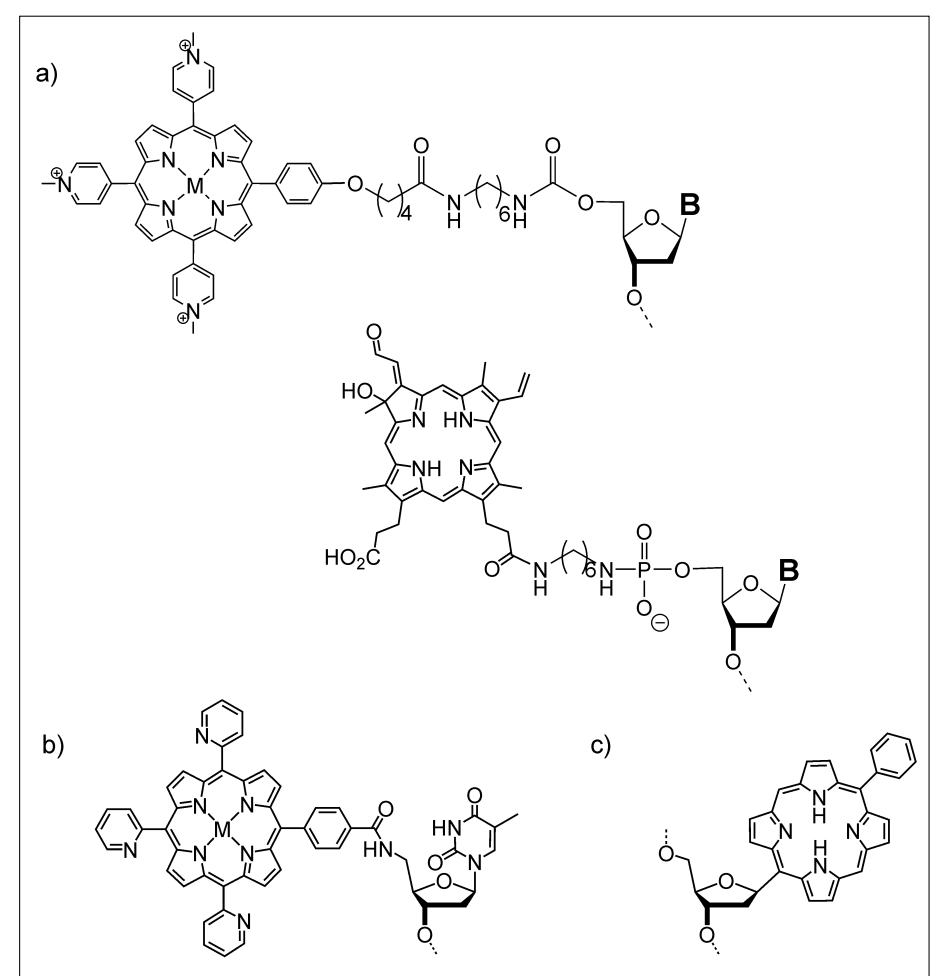

Fig. 3. a) First examples of porphyrinic modifications at the 5 '-end of DNA; b) short linkers for efficient chiral transfer onto porphyrin which is used as chiroptical marker; c) a porphyrin embedded within the base stacking region of DNA. ${ }^{[11-14]}$ 
The porphyrin here is actually positioned within the interior base-stacking region of the DNA, and an abasic site opposite to the porphyrin helps to maintain the integrity of the DNA.

In order to be able to introduce multiple porphyrins at well-defined sites in the DNA, we developed a synthetic route to modified deoxy-uridine using Sonogashira coupling between the commercially available 5-I$\mathrm{dU}$ and alkyne-porphyrins (Scheme 1), starting with tetraphenyl porphyrin (TPP) to give 1. ${ }^{[15]}$ Both hydrophobic and watersoluble derivatives were made by changing the peripheral porphyrin substituents in TPP to carboxy-phenyl. The porphyrin needs to be in a metallated state, which most conveniently is produced by using zinc, in order to avoid copper metallation during the Sonogashira coupling. The zinc is lost during DNA synthesis due to the strongly acidic conditions in removal of the 5'-dimethoxy-trityl (DMT) protecting group and the porphyrins are finally obtained as free base in the oligos. This firstgeneration porphyrin-dU was successfully used to make short oligomers by applying standard phosphoramidite chemistry which forms the basis for automated DNA synthesis. ${ }^{[16]}$ It should be noted that the corresponding phosphoramidites are highly susceptible to oxidation due to the presence of the porphyrin, which is an effective singlet oxygen generator in the presence of light. Thus initial column chromatography had to be performed under strict exclusion of light and oxygen, though we found that precipitation from a DCM-hexane mixture is equally efficient to produce pure material suitable for automated solid phase DNA synthesis. Short di-porphyrin tetranucleotides, including both $\mathbf{1}$ and the more hydrophobic but less sterically hindered diphenyl porphyrin (DPP) 2 , were shown to exhibit strong electronic coupling in the ground state. Formation of a duplex was not evident with these tetra-nucleotides based on NMR studies, apart from when the peptide nucleic acid (PNA) analogue of DNA was used as a charge neutral complement. ${ }^{[17]}$ It was further shown that UV-irradiation of porphyrins in tetranucleotidebisporphyrin arrays in organic solvents leads to selective bleaching of DPP but not of TPP. This was clear from absorbance and CD spectroscopy. The DPP could be stabilised by duplex formation with a complementary PNA-strand. Such behaviour is important to realise when the construction of photonic devices is anticipated.

\section{Multiporphyrin Arrays}

The advantage of using solid-phase synthesis to incorporate porphyrins (and indeed any other functionality) into DNA

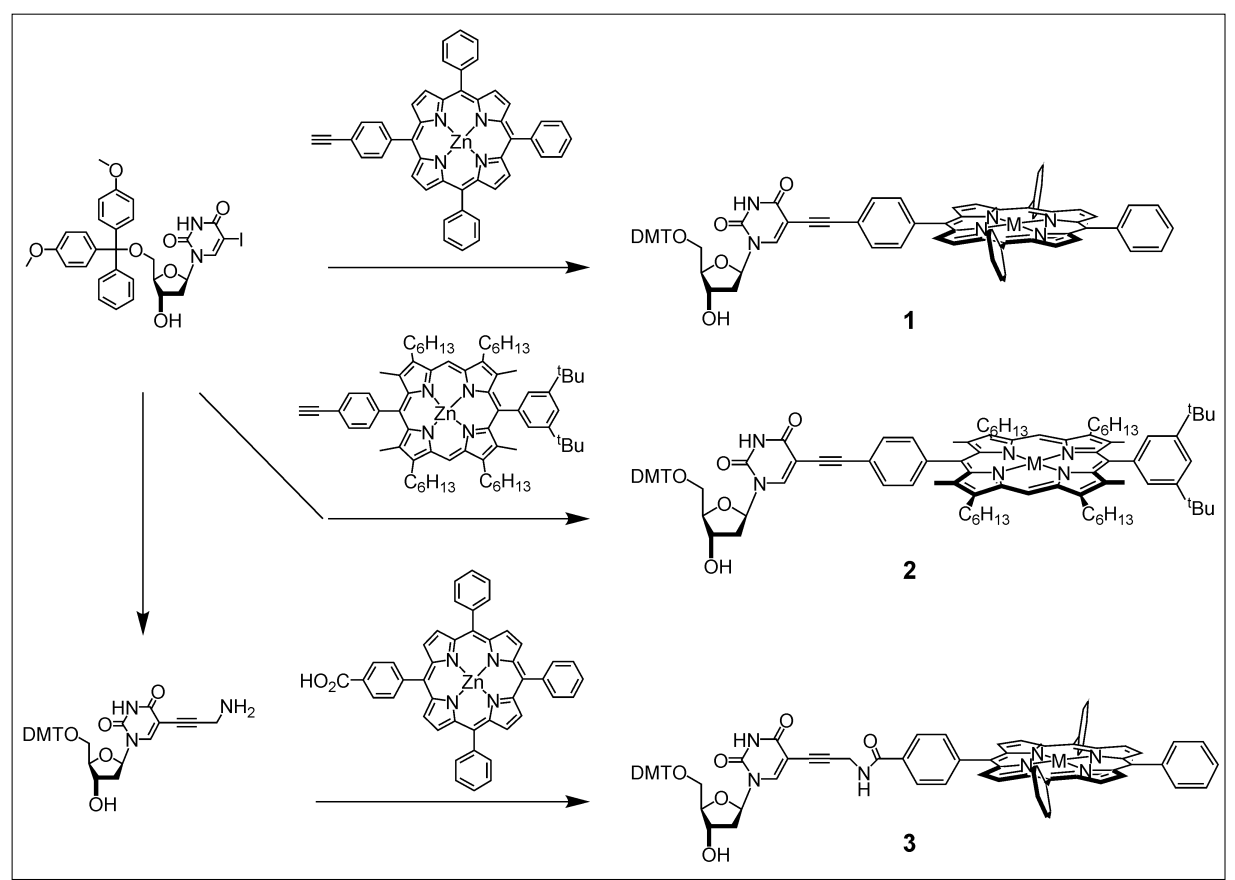

Scheme 1. General synthetic scheme to obtain porphyrin-dU for incorporation into DNA.

is that the building up of supramolecular DNA systems becomes programmable. This way, both $\mathbf{1}$ and $\mathbf{2}$ were successfully incorporated into longer oligonucleotides (ODNs), eventually leading to the desired multi-porphyrin arrays. ${ }^{[18]}$ The purification of the porphyrin-DNA is not as straight forward as many other modified DNA systems due to the presence of the very hydrophobic substituent. Reversed phase high performance liquid chromatography (RP-HPLC) still remains the best strategy, and the use of methanol instead of acetonitrile combined with the use of the more hydrophobic hexafluoro-isopropanol-TEA buffer proved to be most suitable. The attachment of the porphyrin to the 5-position of thymidine leaves the hydrogen bonding pattern untouched allowing duplex formation, and the modifier is positioned towards the major groove of the dsDNA. Correct arrangement in the porphyrin-DNA was confirmed by spectroscopy and molecular modelling (Fig. 4a); the exact structure, however, has yet to be determined and may locally deviate substantially from the idealised duplex, which would be in line with the observed thermodynamic destabilisation of the dsDNA (see below). When a single porphyrin is incorporated into an ODN, its spectroscopic properties are generally unaffected with a single broad absorbance at $420 \mathrm{~nm}$ observable. However, once more porphyrins are incorporated in close proximity, a substantial broadening of the Soret band is observed, identical to the short tetramers described above. This effect is indicative of exciton coupling between the porphyrin moieties, thus the multi-porphyrin DNA exhibits the anticipated properties required towards the creation of electronic wires. We also observed a distinct 'melting' behaviour of the ssDNA when multiple porphyrins are attached, and a strong residual helicity can be seen in the CD spectra, which strongly suggests that the large hydrophobic substituents tend to form helical chromophore stacks even in the single strand. It also poses the question on whether the duplex is actually required to form helical chromophore arrays, to which the answer is in principle No. However, this of course depends on the intended application of the system and needs to be answered on an individual basis.

The first generation of porphyrin-DNA revealed that attachment of porphyrins to one strand led to greatly destabilised duplexes when the dsDNA is formed with a natural complementary strand. The destabilisation is greater for $2\left(\Delta T_{\mathrm{m}}=-7\right.$ ${ }^{\circ} \mathrm{C}$ per porphyrin) compared to $\mathbf{1}\left(\Delta T_{\mathrm{m}}=\right.$ $-3.5{ }^{\circ} \mathrm{C}$ per porphyrin), and is most likely due to local deviation from the ideal DNA structure. Nevertheless, up to eleven porphyrins were incorporated successfully in a row into DNA, which to our knowledge is still the largest number of modifications achieved with such a sterically demanding and hydrophobic substituent. This record number demonstrated for the first time that there is virtually no limitation in the chemical modification of single-stranded DNA, as long as the modifiers are compatible with the conditions of automated DNA synthesis.

The destabilisation of the DNA duplex when only one strand is modified led us to explore an alternative arrangement denoted zipper array, where the porphyrins are now attached to both complementary 
DNA strands. ${ }^{[19]}$ The porphyrins are incorporated at alternating base position, giving an overall $\left(\mathrm{T}^{\mathrm{P}}-\mathrm{A}\right)_{\mathrm{n}}$ repeat sequence rather than a $\left(\mathrm{T}^{\mathrm{P}}\right)_{\mathrm{n}}$ sequence. Upon duplex formation, the porphyrins interlock, leading to the full formation of a porphyrin array, where we have introduced up to twelve porphyrins (Fig. 4b). The stabilising effect is $+0.5{ }^{\circ} \mathrm{C}$ per porphyrin, which in itself does not seem much. Compared to the overall formation of a 12-porphyrin array, however, this accounts for a duplex stabilisation of an impressive $>40{ }^{\circ} \mathrm{C}$ in single strand vs zipper array.[20] Clearly when working with such modifiers, the zipper arrangement is beneficial for stabilisation and should be the way forward. Whether the rigid building block 1 or the more flexible building block $\mathbf{3}$ (obtained by standard peptide coupling of carboxy-porphyrin and propargylamine-dU) ${ }^{[19 a]}$ is used seems to have implications on the overall structure, and to a small extent also on the thermodynamic stability. Whilst homo-porphyrinic systems with either all-1 or all-3 seem to lead to pairwise stacking in both cases, the stabilisation in $\mathbf{3}$ is larger compared to 1. A mixed hetero-array including both 1 and $\mathbf{3}$ in a complementary manner seems to give a more evenly distributed array, but the overall stabilisation is in-between the two homo-arrays. The differences are small, however, and are within one degree for a 12-porphyrin array. In addition, this arrangement allows for selective metallation of one porphyrin sequence, and zinc, copper or cobalt were introduced post-synthetically. A mixed zinc-free base $(\mathrm{Zn}-2 \mathrm{H})$ system shows efficient energy transfer in the annealed duplex state at low temperature, which is absent in the melted single strand system at high temperature. This is reversible through melting-annealing, and represents to our knowledge the first reversible photonic wire based on a DNA templated system.

It has now become evident that the hydrophobic nature of the porphyrin modification has far reaching consequences for the behaviour of the systems, which - in our view - should be taken into account when working with hydrophobic modifications in general (Fig. 4c). From spectroscopic studies (fluorescence, CD, EPR) and XRD we conclude that the porphyrinDNA interacts also intermolecularly. $\left.{ }_{[} 19 \mathrm{a}, 21\right]$ Initial SAXS studies showed the formation of cylindrical entities from the 12-porphyrin zipper array with dimensions of about $4 \times 13 \mathrm{~nm}$, which accounts for a two to four helical bundle. This was later corroborated by EPR spectroscopy using copper-metallated porphyrin-DNA. A strong coupling between the copper centres is observed (half-field signal at around 1600 Gauss), even in single-porphyrin modified DNA, and occurs both in the single- and double-

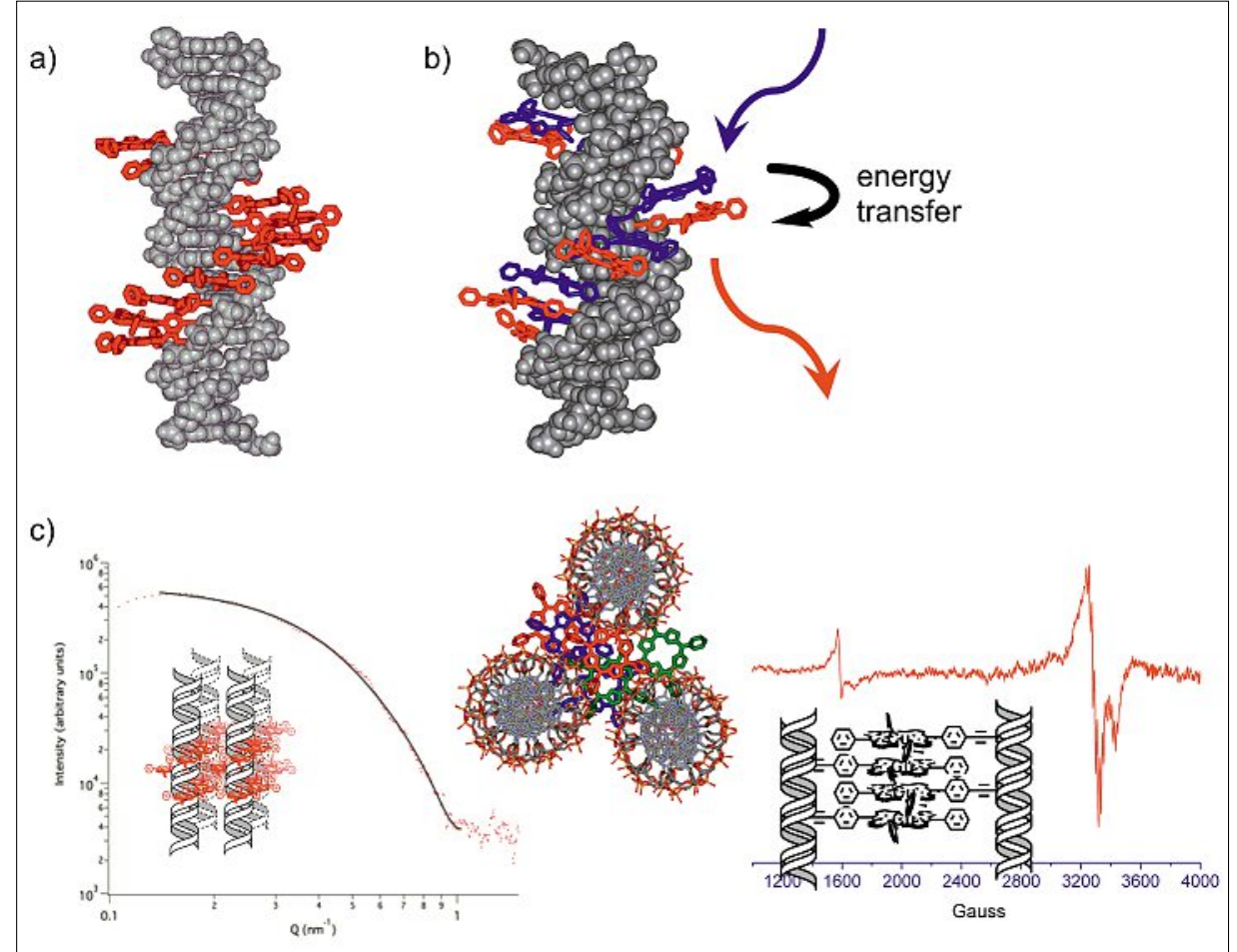

Fig. 4. a) Putative structure of the first generation eleven porphyrin DNA duplex; [18a] b) putative structure of a 12 porphyrin zipper array and energy transfer from zinc-3 (blue) to free base-1 (red):[19] c) SAXS (left) ${ }^{[19 a]}$ and EPR (right) ${ }^{[21]}$ spectra confirming intermolecular interactions arising from bundling of the porphyrin-DNA.

stranded DNA. This is consistent with intermolecular stacking of the porphyrins, and an overall centre-to-centre distance of 6.5-8.9 $\AA$ was determined, depending on number and structure of the porphyrins present, and a minimum of six porphyrins seem to interact. It should be noted that this does not lead to large aggregation and precipitation of the system, but rather discrete bundles are formed which remain soluble in water. The extent of the bundling is dependent on both DNA and salt concentration, and persists above $5 \mu \mathrm{M}$ DNA concentration even in pure water but it is stronger in high salt concentration $(>100$ $\mathrm{mM} \mathrm{NaCl}$ ). Similar intermolecular porphyrin-DNA stacking has been reported, and it might be used in fact as a molecular glue, opening a new level of interactions upon which could be built.

\section{Applications in Sensing, Switching and Nano-architectonics}

The diverse properties of porphyrins can be used to create tailored functional molecules for specific applications. In this part, we describe three examples where porphyrins have shown to be superior to other modifications, but also describe the limitations due to the hydrophobic nature of the modifier (Fig. 5). As outlined above, the porphyrin-array could be used to create reversible energy transfer systems, and we have explored this ability in hairpin DNA (molecular beacon, Fig. 5a) for switching energy transfer states. ${ }^{[22]}$ We created a programmable switch where the DNA is partially self-complementary with repeating ATTA-TAAT box sequences; an additional 13 base sequence allows for specific recognition of complementary strands including various repeats of the complementary ATTA-TAAT box, thus enabling controlled elongation or contraction of the stem region. The beacon was modified with a $\mathrm{Zn}$ $2 \mathrm{H}$ donor-acceptor system and compared to a FAM-TAMRA control. Fluorescence spectroscopy showed that the switchsequences all display a FRET efficiency close to $100 \%$. No variation could be detected in the different conformations, nor upon changing the linker to the porphyrin. Based on the $R_{0}$ value of porphyrins ( $\sim 30$ $\AA$ ), the calculations would predict FRET efficiencies of $\sim 43 \%$ at most. This indicates that the porphyrins are in close contact at a maximum distance of about $3-10 \AA$, which is consistent with the model derived from EPR measurements. The system is therefore disrupted by the hydrophobic interactions of the porphyrins which are stacked to give a very efficient energy transfer between the $\mathrm{Zn}$ - and $2 \mathrm{H}$-porphyrin, and the addition of stabilising complementary strands has no effect on the actual length of the beacon. At this point we cannot rule out intermolecular interactions. In contrast, the FAM-TAMRA system shows very much the expected system-dependent FRET, and a reversible five-state switch can be generated by se- 
lectively elongating the stem and programming the distance of the chromophores, which can be monitored using real time fluorescence spectroscopy. This clearly shows one of the limitations of the system: high FRET can be achieved, but if flexibility is aimed at then more stable systems need to be used to prevent intramolecular porphyrin stacking through rearrangement of the DNA.

Porphyrins are very useful electrochemical tags, and we made use of this property to investigate in electrochemical genosensors based on porphyrin-DNA. In our design, the porphyrin is located close to the electrode surface and shows strong current in the single-stranded state (Fig. 5b). ${ }^{[23]}$ We found that cobalt works best in this case allowing to work in the positive potential where detachment of the DNA from the electrode surface is minimised.
Upon duplex formation with a complementary sequence, the electrochemical signal is diminished greatly. Single nucleotide polymorphism (SNP) can also be detected as single mismatches induces far smaller signal reduction. This 'signal-off' mechanism is rather unusual and is explained by the higher negative charge density of the dsDNA, combined with embedding the porphyrin within the major groove of the DNA, which overall gives limited access of the porphyrin to the electrolyte. Based on the working conditions we estimate that we can measure as few as 1000 DNA molecules, and Avian Influenza Virus-based DNA sequences characteristic for $\mathrm{H} 5 \mathrm{~N}$ were detected at femtomolar levels from competing non-complementary sequences through hybridization of the labeled DNA. We are now working on improving the system for simultaneous detection of different
DNA sequences within the same sample solution using different metals, ${ }^{[24]}$ and also lowering the detection limit of the system ultimately aiming a single molecule detection (or as close as possible).

In terms of larger DNA structures, the use of porphyrins is still in its exploratory stage. While some nanostructures including porphyrins have been reported, the advantage of this modifier has only recently become evident. In one of our projects, we have explored the formation of DNA origami-based nano-pores which are able to mimic the properties of $\alpha$-hemolysin (Fig. 5c). ${ }^{25]}$ This membrane disrupting protein is being investigated as single-molecule DNA sequencing system due to its facile insertion in lipid bilayers, opening a $2 \mathrm{~nm}$ wide pore through which single-stranded DNA can be threaded. The individual nucleobases then lead to a selective reduction

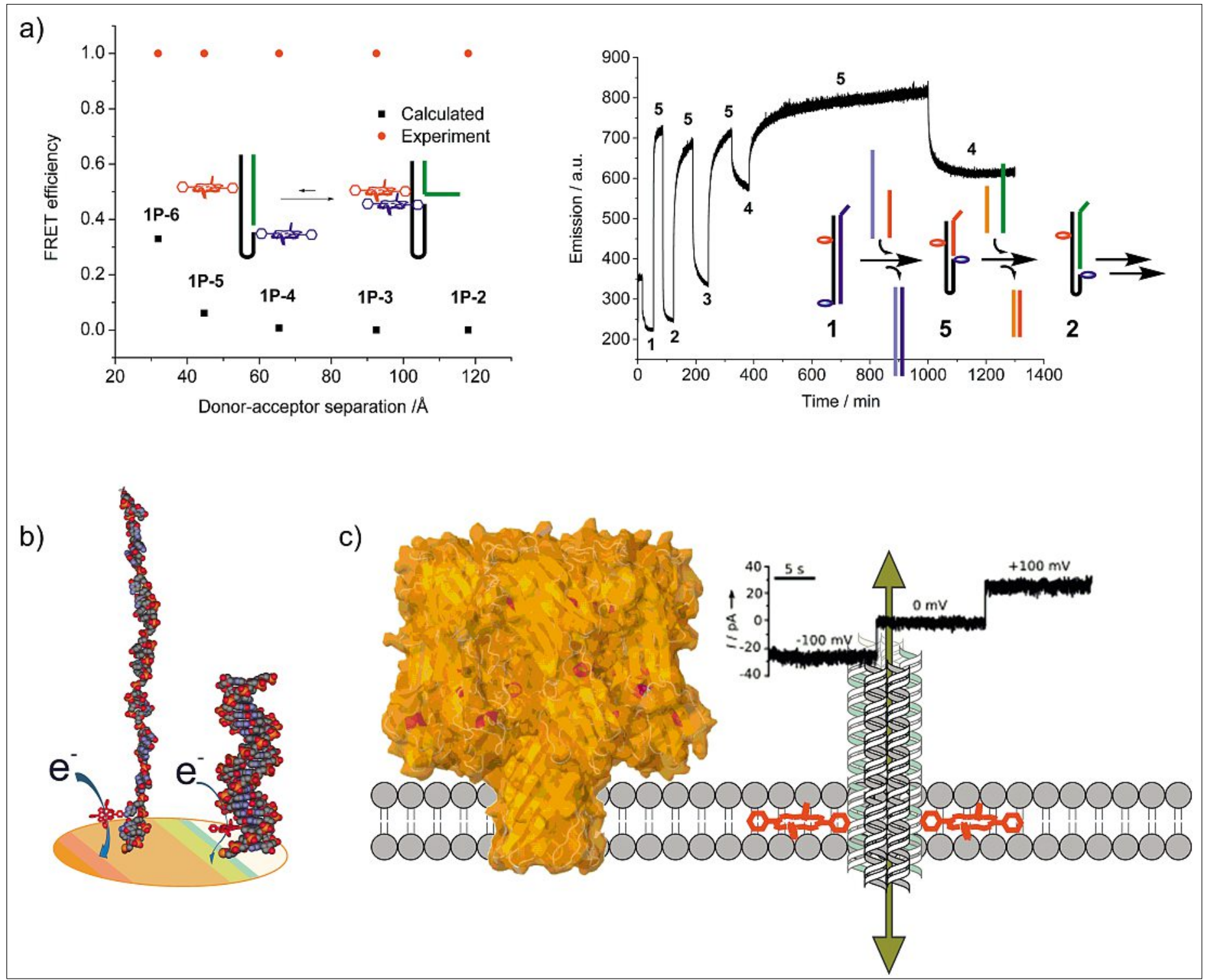

Fig. 5. a) A porphyrin-DNA switch consisting of a partially self-complementary stem-loop sequence (black) stabilised with a complementary strand (green), and FRET efficiencies demonstrating the collapse of the architecture (left), compared to the FAM - TAMRA switch with real-time fluorescence monitoring (right); ${ }^{[22]} \mathrm{b}$ ) schematics of an electrochemical genosensor based on cobalt porphyrin with an efficient 'signal-off' detection of the target sequence; [23] c) DNA origami to create artificial nano-pores, showing the structure of $\alpha$-hemolysin (left) and the porphyrin modified DNA origami insertion into lipid bilayers (not to scale). ${ }^{25 c]}$ 
in ionic current through the pore by blockage, the extent of which is dependent on the nature of the nucleobase. We designed a tubular structure mimicking the stem part of $\alpha$-hemolysin. The DNA nanopores consist of a bundle of six hexagonally arranged duplexes which are interconnected by cross-overs. The DNA pore itself does not insert into lipid bilayers due to its overall negative charge on the outer rim. Initially, we created a hydrophobic belt by inserting phosphorothioates at selected positions, which were then alkylated with iodoethane to add around 72 ethyl groups. This modification overcomes the otherwise inherent energetic mismatch to the hydrophobic environment of the membrane, and the DNA origami efficiently inserts into lipid bilayers and creating an ion channel. Replacement of the $>70$ alkyl groups by only two porphyrins shows that the pore also inserts efficiently into lipid bilayers, which was confirmed by fluorescence spectroscopy and single molecule current measurements. Clearly the hydrophobic character of the porphyrin outweighs the small molecule modification. Thus the porphyrin modified origami punctured the bilayer with nanoscale holes allowing a steady ionic current. The porphyrin actually provides a very convenient handle with dual property, namely a hydrophobic anchor to efficiently embed the negatively charged DNA, which simultaneously acts as a chromophore to monitor the insertion and distribution of the DNA origami in the artificial membrane. This system may prove superior in many applications where the formation of ion channels is desired.

\section{Conclusions and Outlook}

The use of porphyrins in DNA modification has shown to lead to a very versatile system which can be tailored to many different applications. The lipophilicity of the porphyrin can be used to modulate the properties by creating hydrophobic anchors, though intermolecular interactions should not be neglected particularly in aqueous environments. The optical and electrochemical properties clearly will allow for the creation of efficient wires, which we are further pursuing. Part of our research is now focussed on applications in the medicinal field, while also investigating the formation of electronic wires and light pipes, and the connection of porphyrins with other ongoing research in DNA templated synthesis, [26] DNA delivery[27] and diagnostics, ${ }^{[28]}$ and materials chemistry. ${ }^{[29]}$ We believe that there is much to come in the near future, where porphyrins will be combined with other modifiers ${ }^{[30]}$ and assembled using a versatile supramolecular DNA templating approach.
Received: July 21, 2015

[1] a) E. Stulz, Chem.-Eur. J. 2012, 18, 4456; b) E. Stulz, G. Clever, M. Shionoya, C. D. Mao, Chem. Soc. Rev. 2011, 40, 5633; c) T. J. Bandy, A. Brewer, J. R. Burns, G. Marth, T. Nguyen, E. Stulz, Chem. Soc. Rev. 2011, 40, 138; d) R. Varghese, H. A. Wagenknecht, Chem. Commun. 2009, 2615; e) C. Lin, Y. Liu, H. Yan, Biochemistry 2009, 48, 1663; f) M. Endo, H. Sugiyama, ChemBioChem 2009, 10, 2420; g) N. C. Seeman, Nature 2003, 421, 427; h) N. C. Seeman, J. Theor. Biol. 1982, 99, 237; i) 'DNA in Supramolecular Chemistry and Nanotechnology', Eds. E. Stulz, G. H. Clever, John Wiley \& Sons, Inc., 2015, ISBN: 978-1118-69686-6.

[2] a) M. H. F. Wilkins, A. R. Stokes, H. R. Wilson, Nature 1953, 171, 738; b) J. D. Watson, F. H. C. Crick, Nature 1953, 171, 737; c) R. E. Franklin, R. G. Gosling, Nature 1953, 171, 740.

[3] R. Kumar, A. El-Sagheer, J. Tumpane, P Lincoln, L. M. Wilhelmsson, T. Brown, J. Am. Chem. Soc. 2007, 129, 6859.

[4] J. H. Chen, N. C. Seeman, Nature 1991, 350, 631

[5] P. W. K. Rothemund, Nature 2006, 440, 297.

[6] a) S. Woo, P. W. K. Rothemund, Nat. Chem. 2011, 3, 620; b) N. C. Seeman, Nano Lett. 2010, 10, 1971; c) K. Lund, A. J. Manzo, N. Dabby, N. Michelotti, A. Johnson-Buck, J. Nangreave, S. Taylor, R. J. Pei, M. N. Stojanovic, N. G. Walter, E. Winfree, H. Yan, Nature 2010, 465, 206; d) Z. Li, M. H. Liu, L. Wang, J. Nangreave, H. Yan, Y. Liu, J. Am. Chem. Soc. 2010, 132, 13545; e) D. R. Han, S. Pal, Y. Liu, H. Yan, Nat. Nanotechnol. 2010, 5, 712; f) Y. G. Ke, J. Sharma, M. H. Liu, K. Jahn, Y. Liu, H. Yan, Nano Lett. 2009, 9, 2445; g) M. Endo, K. Hidaka, T. Kato, K. Namba, H. Sugiyama, $J$. Am. Chem. Soc. 2009, 131, 15570; h) Y. G. Ke, S. Lindsay, Y. Chang, Y. Liu, H. Yan, Science 2008, 319, 180; i) Y. W. Zhang, N. C. Seeman, J. Am. Chem. Soc. 1994, 116, 1661.

[7] a) M. D. Matteucci, M. H. Caruthers, J. Am Chem. Soc. 1981, 103, 3185; b) S. L. Beaucage, M. H. Caruthers, Tetrahedron Lett. 1981, 22, 1859.

[8] a) E. Mayer-Enthart, H.-A. Wagenknecht, Angew. Chem. Int. Ed. 2006, 45, 3372; b) P. Roethlisberger, F. Wojciechowski, C. J. Leumann, Chem.-Eur. J. 2013, 19, 11518; c) J. Wengel, Org. Biomol. Chem. 2004, 2, 277; d) S. I. Khan, A. E. Beilstein, M. W. Grinstaff, Inorg. Chem. 1999, 38, 418; e) M. Nakamura, Y. Shimomura, Y. Ohtoshi, K. Sasa, H. Hayashi, H. Nakano, K. Yamana, Org. Biomol. Chem. 2007, 5, 1945; f) M. Probst, S. M. Langenegger, R. Häner, Chem. Commun. 2014, 50, 159.

[9] F. W. Hobbs, J. Org. Chem. 1989, 54, 3420.

[10] a) S. Jager, G. Rasched, H. Kornreich-Leshem, M. Engeser, O. Thum, M. Famulok, J. Am. Chem. Soc. 2005, 127, 15071; b) O. Thum, S. Jager, M. Famulok, Angew. Chem. Int. Ed. 2001, 40, 3990.

[11] C. Casas, C. J. Lacey, B. Meunier, Bioconjugate Chem. 1993, 4, 366.

[12] A. S. Boutorine, D. Brault, M. Takasugi, O. Delgado, C. Hélène, J. Am. Chem. Soc. 1996, 118,9469

[13] a) A. Mammana, G. Pescitelli, T. Asakawa, S. Jockusch, A. G. Petrovic, R. R. Monaco, R. Purrello, N. J. Turro, K. Nakanishi, G. A. Ellestad, M. Balaz, N. Berova, Chem. Eur. J. 2009, 15, 11853; b) A. D’Urso, A. Mammana, M. Balaz, A. E. Holmes, N. Berova, R. Lauceri, R. Purrello, J. Am. Chem. Soc. 2009, 131, 2046; c) A. Mammana, T. Asakawa, K. Bitsch-Jensen, A. Wolfe, S. Chaturantabut, Y. Otani, X. X. Li, Z. M. Li, K. Nakanishi, M. Balaz, G. A. Ellestad, N. Berova, Bioorg. Med. Chem. 2008,
16, 6544; d) N. Berova, L. D. Bari, G. Pescitelli, Chem. Soc. Rev. 2007, 36, 914; e) M. Balaz, B. C. Li, J. D. Steinkruger, G. A. Ellestad, K. Nakanishi, N. Berova, Org. Biomol. Chem. 2006, 4, 1865; f) M. Balaz, M. De Napoli, A. E. Holmes, A. Mammana, K. Nakanishi, N. Berova, R. Purrello, Angew. Chem. Int. Ed. 2005, 44, 4006; g) A. D’Urso, A. E. Holmes, N. Berova, M. Balaz, R. Purrello, Chem.-Asian J. 2011, 6, 3104 .

[14] H. Morales-Rojas, E. T. Kool, Org. Lett. 2002, 4, 4377 .

[15] a) I. Bouamaied, E. Stulz, CHIMIA 2005, 59, 101; b) I. Bouamaied, E. Stulz, SYNLETT 2004, 1579 .

[16] I. Bouamaied, L. A. Fendt, M. Wiesner, D. Häussinger, N. Amiot, S. Thöni, E. Stulz, Pure Appl. Chem. 2006, 78, 2003.

[17] I. Bouamaied, E. Stulz, SYNLETT 2009, 2913.

[18] a) L. A. Fendt, I. Bouamaied, S. Thöni, N. Amiot, E. Stulz, J. Am. Chem. Soc. 2007, 129, 15319; b) I. Bouamaied, L. A. Fendt, D. Häussinger, M. Wiesner, S. Thöni, N. Amiot, E. Stulz, Nucleosides Nucleotides Nucleic Acids 2007, 26, 1533; c) I. Bouamaied, T. Nguyen, T. Rühl, E. Stulz, Org. Biomol. Chem. 2008, 6, 3888 .

[19] a) A. Brewer, G. Siligardi, C. Neylon, E. Stulz, Org. Biomol. Chem. 2011, 9, 777; b) T. Nguyen, A. Brewer, E. Stulz, Angew. Chem. Int. Ed. 2009, 48, 1974.

[20] H. A. Wagenknecht, Angew. Chem. Int. Ed. 2009, 48, 2838.

[21] T. Nguyen, P. Hakansson, R. Edge, D. Collison, B. A. Goodman, J. R. Burns, E. Stulz, New J. Chem. 2014, 38, 5254.

[22] J. R. Burns, S. Preus, D. G. Singleton, E. Stulz, Chem. Commun. 2012, 48, 11088.

[23] I. Grabowska, D. G. Singleton, A. Stachyra, A. Gora-Sochacka, A. Sirko, W. ZagorskiOstoja, H. Radecka, E. Stulz, J. Radecki, Chem. Commun. 2014, 50, 4196.

[24] I. Grabowska, M. Zborowska, N. T. Nguyen, W. Dehaen, E. Stulz, J. W. Wood, H. Radecka, J. Radecki, Int. J. Electrochem. Sci. 2014, 9, 5948.

[25] a) J. R. Burns, K. Gopfrich, J. W. Wood, V. V. Thacker, U. F. Keyser, E. Stulz, S. Howorka, Biophys. J. 2014, 106, 632A; b) J. R. Burns, E. Stulz, S. Howorka, Nano Lett. 2013, 13, 2351; c) J. R. Burns, K. Gopfrich, J. W. Wood, V. V. Thacker, E. Stulz, U. F. Keyser, S. Howorka, Angew. Chem. Int. Ed. 2013, 52, 12069.

[26] a) P. J. Milnes, M. L. McKee, J. Bath, L. J. Song, E. Stulz, A. J. Turberfield, R. K. O'Reilly, Chem. Commun. 2012, 48, 5614; b) M. L. McKee, P. J. Milnes, J. Bath, E. Stulz, R. K. O'Reilly, A. J. Turberfield, J. Am. Chem. Soc. 2012, 134, 1446; c) M. L. McKee, A. C. Evans, S. R. Gerrard, R. K. O'Reilly, A. J. Turberfield, E. Stulz, Org. Biomol. Chem. 2011, 9, 1661; d) M. L. McKee, P. J. Milnes, J. Bath, E. Stulz, A. J. Turberfield, R. K. O'Reilly, Angew. Chem. Int. Ed. 2010, 49, 7948 .

[27] T. R. Wilks, A. Pitto-Barry, N. Kirby, E. Stulz, R. K. O'Reilly, Chem. Commun. 2014, 50, 1338.

[28] P. Kongsuphol, H. H. Ng, J. P. Pursey, S. K. Arya, C. C. Wong, E. Stulz, M. K. Park, Biosens. Bioelectron. 2014, 61, 274.

[29] a) R. Zmijan, M. Carboni, L. Capretto, E. Stulz, X. L. Zhang, RSC Adv. 2014, 4, 14569; b) M. Carboni, L. Capretto, D. Carugo, E. Stulz, X. L. Zhang, J. Mater. Chem. C 2013, 1, 7540.

[30] M. Vybornyi, A. L. Nussbaumer, S. M. Langenegger, R. Häner, Bioconjugate Chem. 2014, $25,1785$. 